\title{
O REDIMENSIONAMENTO DAS VULNERABILIDADES NO ÂMBITO DA RELAÇÃO MÉDICO-PACIENTE DIANTE DA COVID-19 NO CONTEXTO PANDÊMICO BRASILEIRO
}

\author{
THE RESEARCH OF VULNERABILITIES IN THE FRAMEWORK OF THE MEDICAL- \\ PATIENT RELATIONSHIP BEFORE COVID-19 IN THE BRAZILIAN PANDEMIC CONTEXT
}

\author{
Ana Thereza Meirelles Araújo ${ }^{1}$ \\ UNEB/ UCSal/ Fac. Baiana de Direito \\ Liliane Lins-Kusterer ${ }^{2}$ \\ Universidade Federal da Bahia (UFBA)
}

\begin{abstract}
Resumo:
Artigo destinado a refletir sobre a conformação do panorama de vulnerabilidades no âmbito da relação médicopaciente, a partir do cenário instaurado pela pandemia do COVID-19. Buscou-se avaliar a mudança paradigmática de atuação do Direito e da Medicina em face das demandas decorrentes do contexto pandêmico, considerando o atual estado de conhecimento científico da doença. Foram aportadas as noções conceituais e tipológicas da ideia de vulnerabilidade, considerando suas dimensões ontológica ou universal e circunstanciais ou secundárias. No âmbito da saúde, buscou-se identificar o acréscimo e a potencialização de vulnerabilidades às partes dentro da relação médico-paciente a partir das diversas situações relacionadas à pandemia.
\end{abstract}

Palavras-chave:

vulnerabilidade na relação médico-paciente. Bioética e direito. pandemia.

\begin{abstract}
:
Article designed to reflect on the conformation of the vulnerability panorama within the scope of the doctor-patient relationship, based on the scenario created by the pandemic of COVID-19. We sought to assess the paradigmatic change in the practice of Law and Medicine in the face of the demands arising from the pandemic context, considering the current state of scientific knowledge of the disease. The conceptual and typological notions of the idea of vulnerability were brought in, considering its ontological or universal and circumstantial or secondary dimensions. In the area of health, we sought to identify the increase and potentiation of vulnerabilities to the parties within the doctor-patient relationship, based on the various situations related to the pandemic.
\end{abstract}

Keywords:

vulnerability in the medical-patient relationship. bioethics and law. pandemic.

\footnotetext{
${ }^{1}$ Pós-Doutoranda em Medicina pelo Programa de Pós-Graduação de Medicina e Saúde da Faculdade de Medicina da Universidade Federal da Bahia (UFBA). Doutora em Relações Sociais e Novos Direitos pela Faculdade de Direito da Universidade Federal da Bahia (UFBA). Mestre em Direito Privado e Econômico pela Faculdade de Direito da Universidade Federal da Bahia (UFBA). Professora do Programa de Pós-Graduação em Direitos Fundamentais e Alteridade da Universidade católica do Salvador (UCSAL). Professora da Universidade do Estado da Bahia (UNEB). Professora da Faculdade Baiana de Direito. Coordenadora da Pós-graduação em Direito Médico, da Saúde e Bioética da Faculdade Baiana de Direito. Líder do Grupo de Pesquisa JusBioMed - Direito, Bioética e Medicina.

${ }^{2}$ Pós-Doutora em Medicina e Saúde Humana pela Escola Bahiana de Medicina e Saúde e Saúde Pública. Livre Docente em Bioética pela Faculdade de Medicina da Bahia (FMB-UFBA). Doutora em Patologia Humana pelo Centro de Pesquisa Gonçalo Moniz /BA. Pesquisadora Visitante da EBMSP. Professora do Departamento de Medicina Preventiva e Social da FMB-UFBA e professora permanente do Programas de Pós-graduação em Saúde, Ambiente e Trabalho (FMB-UFBA). Coordenadora do Programa de Pós-Graduação em Medicina e Saúde (FMBUFBA).
} 


\section{INTRODUÇÃO}

A possibilidade de vivenciar uma pandemia era pouco pensada pela maioria das pessoas. A doença que instaurou o contexto pandêmico possui características ainda cientificamente desconhecidas, que fugiram também ao grau de previsibilidade pelo ser humano, levando em consideração a capacidade de contaminação, de evolução e de comprometimento da saúde, bem como a possibilidade de portar o vírus em condição assintomática.

A contaminação da espécie humana pela doença demanda respostas imediatas da Ciência que ainda não foram seguramente possíveis. O desconhecimento científico é, pois, a realidade da pandemia ocasionada pelo coronavírus, tendo em vista que as respostas, tanto medicamentosas quanto vacinais, precisam de um tempo razoável para se consolidarem como protocolos seguros e para serem adequadamente distribuídas para todos os seres humanos do planeta.

A necessidade de encontrar o ponto adequado de controle da Ciência sobre o vírus que continua a se espalhar é evidente, de modo que é evidente a dimensão do esforço científico global que busca os protocolos e as respostas até então faltantes. Constatar a atual ausência de alternativas terapêuticas totalmente eficazes revela uma nova condição paradigmática, acentuada pelas realidades socioeconômicas, como a desigualdade social, o não acesso a direitos básicos e fundamentais e a ausência ou ineficiência do Estado, enquanto único ente que detém a possibilidade de efetivar medidas capazes de atenuar as catástrofes previsíveis decorrentes dessa pandemia.

No Brasil, uma série de fatores culminam para a composição de um cenário complexo e preocupante. A esfera socioeconômica pressupõe um complexo de problemas que fomentam a cada vez mais evidente condição de vulnerabilidade humana, seja da população como um todo, seja de grupos que pertencem às diversas esferas específicas da vulnerabilidade, como a pobreza, as condições de saúde, a idade, a profissão e outras.

Dentro das relações de saúde, torna-se necessária investigação detalhada que aponte o redimensionamento das vulnerabilidades dos sujeitos envolvidos, o que engloba o paciente, o médico e os demais profissionais da saúde. A relação médico-paciente demandará, então, a atenção a outros elementos que brotaram da condição pandêmica.

A proposta é um estudo analítico, de cunho teórico, que avalie a ideia pré-existente de vulnerabilidade em cotejo à realidade pandêmica. As reflexões aqui traçadas visam descortinar e analisar a dimensão atual das vulnerabilidades no contexto brasileiro, a partir de considerações biojurídicas concernentes às situações que acentuaram as condições de fragilidade e risco dos 
sujeitos que integram as relações de saúde: pacientes, médicos e demais profissionais.

\section{DIREITO E MEDICINA: NOVOS PARADIGMAS NO CONTEXTO PANDÊMICO}

A lógica de construção da relação entre Medicina e Direito era posta, consideravelmente, antes da pandemia, mediante uma outra realidade. No contexto brasileiro, a dinâmica da relação entre as áreas se estabelecia, em maioria, mediante o pressuposto causa e consequência. A Medicina era determinante para a causa do fato e o Direito regulamentava o fato e a sua respectiva consequência. $\mathrm{O}$ que se podia verificar, então, na grande maioria das vezes, era que a prática da atividade médica ou científica era disciplinada normativamente pelo Direito, ou seja, para que a análise jurídica ocorresse, era necessário partir de um fenômeno médico.

Em síntese, nesta relação entre as áreas, a dinâmica da regulamentação pela norma jurídica era estabelecida a partir das possibilidades emanadas das descobertas da Medicina. Não havia sentido em regulamentar ou disciplinar juridicamente aquilo que não se consolidou como um achado científico. Acrescente-se a isso, claro, a existência de disciplina normativa, por meio de Resolução, para condução ética das pesquisas clínicas no país.

Para explicar a marcha de construção dos conhecimentos científicos, Hans Jonas (2013, p.53) faz importante reflexão sobre a inevitabilidade da aplicação de um saber descoberto. De forma geral, "a posse de uma capacidade ou poder (por indivíduos ou grupos) não significa seu uso. Ela pode arbitrariamente permanecer em repouso por longo tempo, pronta para uso, para, ocasionalmente, entrar em ação, segundo o desejo e o critério do sujeito" (JONAS, 2013, p.53). No entanto, essa relação clara que diferencia poder e fazer, saber e aplicação, não é válida quando se trata de capacidades técnicas perante a forma com que a nossa sociedade está estruturada. Na Medicina, a possibilidade que emana da técnica é incessantemente perseguida, o que, por muitas vezes, pode implicar em vilipêndio de pressupostos éticos.

Assim, a evolução dos achados científicos sempre foi pressuposta à disciplina normativa, de modo que "em um tempo marcado pela instabilidade e no qual os significados são constantemente restabelecidos, a possibilidade de existência de uma moldura axiológica rígida capaz de orientar uniformemente as ações parece difícil” (MINAHIM, 2005, p.25). Na lógica clássica de atuação do Direito, regulamentar e disciplinar os achados da Ciência já apontava uma tarefa demasiadamente complexa. A dinâmica pré-pandêmica já evidenciava a difícil missão de regulamentar os fenômenos nascidos da Medicina e pouco compreendidos pelos operadores do Direito. 
Historicamente, a Medicina precede o Direito. As práticas de cura e de busca de respostas orgânicas a partir de determinados rituais com recursos da natureza revelam a semente do intento da Medicina primitiva. O Direito pode ser traduzido como uma construção social inicialmente anarquizada, já que seu objeto de estudo e de atuação tem viés mais abrangente e generalista. Essa dinâmica histórica corrobora o paradigma pré-pandêmico: diante do fato gerado pela Medicina, atua o Direito em prol da construção da disciplina que permita ou proíba as condutas, através da imposição de limites.

O desenvolvimento de qualquer área da Ciência, o que inclui tanto a Medicina quanto o Direito, notadamente, não pode ser desvinculado dos comandos da Ética. É, pois, a Ética um pressuposto que deve incidir pontualmente na construção dos resultados científicos, a fim de legitimá-los e qualificá-los como tais.

Essa lógica da ordem de incidência das duas áreas, considerando, talvez, não apenas a realidade brasileira, aponta para uma importante mudança de direção diante do contexto pandêmico. Agora, mesmo não tendo a Medicina respostas concretas, seguras e imediatas, considerando a vacina, que está ainda longe de ser distribuída para todos os seres humanos, e os remédios que ainda não apresentam resultados capazes de controlar efetivamente quadros clínicos críticos, o Direito passou a ser severamente demandado, cabendo ao mesmo regulamentar uma série de possibilidades (e não certezas) e de novas demandas originadas no âmago das relações de saúde.

Esse rompimento da lógica clássica e a construção de outra forma de dinamicidade entre as áreas descortina um outro paradigma (KUHN, 2007). A urgente normatização demandada à Ciência Jurídica revela uma outra forma de atuação científica. Rompe-se com o paradigma anterior, que atuava mediante a regulamentação de fenômenos muito mais sólidos e seguros, e busca-se a disciplina normativa, em muitos casos, da probabilidade e dos elementos e informações ainda passíveis de confirmação. Essa nova realidade, mesmo com tantas dificuldades, não pode romper a ideia nuclear de responsabilidade do ser humano para com sua própria espécie, já que toda técnica precisa de ética (JONAS, 2013).

Em sua dimensão originária, a Ciência "e o seu objetivo de ampliar sempre mais o âmbito do saber humano demanda um processo inevitável e permanente de investigação e liberdade. Esse objetivo poderá alcançar fins esperados e não esperados, tanto na sua consecução quanto nos seus resultados" (GARCIA, 2004, p.61). Todo processo de investigação científica é conduzido pelos elementos da temporalidade, da liberdade de pesquisa, com observância dos limites éticos e jurídicos, e da técnica, conhecimento prévio adquirido a partir de outros achados da Ciência (GARCIA, 2004). 
Na lógica de Kuhn (2007), pode-se concluir que a pandemia originou uma espécie de crise científica por descortinar uma nova dinâmica de conformação. "Suponhamos que as crises são uma pré-condição necessária para a emergência de novas teorias e perguntemos então como os cientistas respondem à sua existência" (KUHN, 2007, p.107). A resposta à crise científica posta pela pandemia culmina na necessidade de fazer atuar o Estado, e consequentemente a Ciência jurídica, mediante o sistema de proibições e concessões e através da escolha de valores que pareçam razoáveis à necessidade de preservação da vida e da saúde humanas.

Essa dimensão de responsabilidade dos Estados, em foco, aqui, o brasileiro, passa pela necessidade de políticas públicas dos poderes executivo e legislativo e jurisdição efetiva do poder judiciário, todos em prol de diminuir as vulnerabilidades pré-existentes à pandemia e visivelmente agravadas por esse novo contexto. É certo que a identificação e o estudo de possíveis políticas públicas pertinentes à diminuição de vulnerabilidades, descortinadas ou agravadas pelo contexto pandêmico, fogem ao objeto proposto neste artigo, mas, são consequências do desvelamento de tais vulnerabilidades.

Dentro do exposto, frisa-se que o Direito, enquanto ciência que se propõe à disciplina das condutas humanas para garantir a existência e a integridade de bens jurídicos, diante da pandemia, foi e é incessantemente chamado para intervir de diferentes formas. A intervenção se concretiza pela edição de um complexo jurídico normativo de natureza múltipla (leis ordinárias, decretos, resoluções, portarias, instruções e outros) e pela atividade profissional de agentes públicos e privados, que envolve também a jurisdição.

\section{APORTES FUNDAMENTAIS SOBRE A IDEIA DE VULNERABILIDADE}

O estudo da vulnerabilidade é, sobretudo, um desafio de pesquisa. Isto porque é ela de interesse multidisciplinar, na medida em que é capaz de revelar circunstâncias plúrimas e, consequentemente, evidenciar o agrupamento de elementos complexos, de difícil identificação, muitas vezes, por estarem inseridos na dimensão subjetiva de uma pessoa ou de determinados grupos de pessoas.

Trazendo a vulnerabilidade para a dimensão médico-jurídica, pode-se constatar a sua inegável amplitude, por abranger áreas da ética clínica, da ética em pesquisa e da ética nas políticas públicas (MACKLIN, 2004, p.59).

Miguel Kottow, citando Herder, afirma que, à medida em que os seres humanos foram reconhecidos "como criaturas impotentes comprometidas com a incerta tarefa de desenvolver o próprio ser contado apenas com as suas forças culturais, a filosofia tem considerado a 
vulnerabilidade uma dimensão antropológica essencial da existência humana" (KOTTOW, 2004, p.71). O ponto de partida de qualquer construção teórica da ideia de vulnerabilidade é a sua concepção enquanto dimensão prévia e essencial da existência do ser humano. Somos, pois, ontologicamente vulneráveis simplesmente pelo fato de existirmos.

Compreender a vulnerabilidade como condição humana é assumir que somos vulneráveis e precisamos de proteção, ideia que permeia uma universalidade de culturas. A proposta de combate à vulnerabilidade humana, em seu sentido universal, está no desenvolvimento de culturas e estruturas sociais políticas voltadas para essa finalidade. "As diferenças entre tradições culturais ou sociais parecerem refletir prioridades em termos de riscos percebidos e da proteção preferida contra a vulnerabilidade", no entanto, independentemente das diferenças, parece existir uma noção universal sobre as ameaças à condição de existência humana (SASS, 2004, p.79-80).

É certo que o reconhecimento da existência de uma noção universal não anula a capacidade de identificação de práticas políticas e sociais que contrariem essa ideia global. Lidar com a vulnerabilidade é, também, combater a contrariedade entre ideias teoricamente assumidas ou defendidas politicamente e a sua não execução.

O significado etimológico e conceitual de vulnerabilidade pode ser compreendido como "palavra de origem latina, derivando de vulnus(eris), que significa "ferida". Assim sendo, a vulnerabilidade é irredutivelmente definida como susceptibilidade de se ser ferido" (PATRÃO NEVES, 2006, p.158). Ou, ainda, "ser vulnerável significa estar suscetível a, ou em perigo de, sofrer danos", nesse sentido, acrescenta Kottow que "estar vivo é uma improbabilidade biológica altamente vulnerável a perturbações e à morte, e mais ainda se vidas humanas qua humanas têm de ser construídas, sendo, portanto, desproporcionalmente frágeis e propensas à desordens e disfunções”. (KOTTOW, 2004, p.72).

Essa primeira ideia de vulnerabilidade como uma condição ontológica existencial da espécie é categoricamente reconhecida como vulnerabilidade intrínseca. "A essência da humanidade é a vulnerabilidade", de modo que "conviver com a morte e com a perda de funções que a doença pode trazer é central à vivência de uma vida moral como ser humano" (CAMPBELL, 2004, p.88).

A vulnerabilidade é, na verdade, uma condição de sujeição a todos os seres vivos. "O ser humano e os demais animais têm em comum um tipo de defesa frente à vulnerabilidade - é a defesa instintiva, decorrente do instinto da sobrevivência”, a diferença é que o ser humano "além do instinto da sobrevivência, pode ter noção, ciência e consciência de que ele é vulnerável, com a consequente "angústia" decorrente desse fato" (HOSSNE, 2009, p.42). 
A ideia do que possa ser concebido como vulnerabilidade também pode ser o "grau de suscetibilidade ou de risco a que está exposta uma população em sofrer danos por desastres naturais". Isso incluiria "a relação existente entre a intensidade do dano e a magnitude de uma ameaça, evento adverso ou acidente. Contempla, também, a probabilidade de uma determinada comunidade ou área geográfica ser afetada por uma ameaça ou risco potencial de desastre" (BERTOLOZZI et al, 2009, p.1327). Da derivação da ideia de vulnerabilidade associada à ideia de risco, é possível estabelecer algumas diferenças. O risco deve ser concebido a partir de uma realidade concreta e pontual que circunstancialmente pode atingir uma pessoa ou um grupo de sujeitos, a vulnerabilidade é uma condição que pertence à esfera da vida do indivíduo a partir de fatores individuais abstratos.

A Medicina, o Direito e a Bioética conformam estudos da vulnerabilidade que comportam também perspectivas a partir das realidades em concreto, como a bioética brasileira da intervenção (GARRAFA, 2005), que considera fundamental, dentro de qualquer análise, partir das múltiplas circunstâncias que potencializam a exposição e a desigualdade entre pessoas e grupos sociais.

Como pressuposto prévio para compreender a multiplicidade da incidência da vulnerabilidade, pode-se entender que

\footnotetext{
O ser humano é sempre vulnerável; ele pode ou não estar em situação de vulnerabilidade. Portanto, ser vulnerável o ser humano é sempre; estar vulnerável pode ser sim ou não. Trata-se de ir de uma situação latente a uma situação manifesta; de uma situação de possibilidade para uma situação de probabilidade, do ser vulnerável ao estar vulnerável. Estas oscilações acompanham todas as situações que envolvem a Bioética (HOSSNE, 2009, p.42).
}

Enquanto a vulnerabilidade intrínseca é uma condição universal, comunicável a todos os seres humanos, a vulnerabilidade circunstancial, também conhecida como extrínseca ou secundária, se manifesta a partir de situações que individualizam pessoas ou grupos, como a pobreza, o não acesso à educação, as doenças, a discriminação (KOTTOW, 2004, p.71), ou, ainda, outras circunstâncias capazes de fomentar a suscetibilidade de ser ferido. "A vulnerabilidade adquirida ou secundária cria a suscetibilidade a ser afetado pelo infortúnio causado por alguma aflição subjacente" (KOTTOW, 2004, p.72). Essa categoria de vulnerabilidade comporta um plexo extenso de possibilidades que podem ser manifestar levando em consideração gênero, raça, idade, características físicas, profissão e outras variáveis. 
A constatação das vulnerabilidades adquiridas demanda um olhar adequado à solução das circunstâncias que podem envolver pessoas que titularizam essa condição. A principal resposta às vulnerabilidades dessa natureza pressupõe intervenções por políticas públicas voltadas à realidade que justifica a observância da suscetibilidade de ser ferido, que podem envolver, por exemplo, a construção de legislações específicas, dentre outras alternativas.

Para o estudo da elaboração e do equacionamento das questões que envolvem a Bioética (em sentido amplo e não apenas em biomedicina), adota Willian Saad Hossne (2009, p.42) o apontamento dos "referencias" e não de princípios fundamentais como proposto pela bioética principialista (BEAUCHAMP; CHILDRESS, 1979). A “teoria dos referenciais”, proposta pelo autor, "engloba os clássicos princípios da autonomia, da não maleficência, da beneficência e da justiça não como "princípios", nem como direitos ou deveres, mas como pontos de referência", acrescentando outros, como a vulnerabilidade (HOSSNE, 2009, p.42).

Vulnerabilidades secundárias se expressam significativamente no âmbito das relações em saúde, incluindo questões sobre o acesso (ou a adequação de acesso) ao direito e a relação entre médicos e pacientes. Dentro dessa perspectiva, José Ricardo Ayres e outros (2003, p.23) apontam a necessidade de conceber a vulnerabilidade como a "chance de exposição das pessoas ao adoecimento". Essa chance de ser exposto tem relação imediatamente direta com um complexo de fatores individuais e sociais, que envolvem o acesso a direitos fundamentais.

Dentro das relações de saúde, em especial em situações que envolvem pesquisas clínicas, pode-se perceber a incidência constante de discussões referentes à ideia de vulnerabilidade. Os Documentos Internacionais (como a Declaração de Helsinque e as Declarações de Bioética) e as Resoluções brasileiras (Res. CNS 466/2012 e 510/2016) sobre pesquisa refletem a preocupação em disciplinar situações que envolvem possíveis condições de vulnerabilidade do participante de pesquisa. A ideia de vulnerabilidade no âmbito de estudos clínicos é uniformemente admitida na medida em que a pesquisa seja, por exemplo, um teste de fármaco ou de protocolo experimental invasivo.

No âmbito da relação médico-paciente, em contextos de não pesquisa, a vulnerabilidade também se concretiza de maneiras distintas, passando-se, em seguida, a estudá-la a partir do cenário pandêmico.

\section{VULNERABILIDADES NA RELAÇÃO MÉDICO-PACIENTE E CONTEXTO PANDÊMICO}


A noção inicial que precisa ser fixada como uma realidade global e que precede a qualquer constatação ao contexto pandêmico é a de que a vulnerabilidade é, pois, uma condição humana universal. Nesse sentido, caminharam a Filosofia e os estudos em Bioética nos últimos trinta anos, o que culminou na necessidade de pensar que a realidade existencial do ser humano deva orbitar em torno de tal pressuposto. A pandemia acentua a capacidade de percepção dessa condicionante, dadas as consequências em que a contaminação pelo vírus pode acarretar.

Somando-se a ideia da vulnerabilidade humana como condição universal à pandemia do COVID-19 no Brasil, diversas questões precisam ser pontuadas. O acentuado grau de disseminação do vírus, quando "associado à sua ocorrência numa população completamente suscetível, ocupando territórios extremamente heterogêneos quanto às condições de vida, apontam para o risco diferenciado de ocorrência da COVID-19" (CALDAS DOS SANTOS et al, 2020, p.2).

No Brasil, a desigualdade socioeconômica é latente e tem sido fator determinante para o alto índice de disseminação da doença. A ocupação irregular, desorganizada e não estruturada dos solos urbanos, em especial, nas capitais ou grandes cidades brasileiras, é descortinadora da dificuldade de um controle epidemiológico.

No contexto brasileiro, "o panorama é incerto e as estimativas válidas e confiáveis do número de casos e óbitos por COVID-19 esbarram na ausência de dados confiáveis, seja dos casos ou da implantação efetiva das medidas de supressão, frente às recomendações contraditórias das autoridades em cada nível de governo" (WERNECK; CARVALHO, 2020, p.3). Diversos estudos, conduzidos por especialistas oriundos de áreas distintas, mas que se interseccionam, tentam apontar evidências que orientem e direcionem políticas públicas, considerando as condições agravadoras de vulnerabilidade em que determinados grupos populacionais estão inseridos.

Prospecções especializadas mostram o desastre econômico-social que a pandemia deixará em países latino-americanos. Sabe-se, inclusive, o abismo que diferenciará, ainda mais, as consequências da pandemia entre países do hemisfério norte e países do hemisfério sul (EDITORIAL DEVELOPING WORLD BIOETHICS, 2020). Antes da crise pandêmica, a maioria dos países latino-americanos enfrentava problemas relacionados à governança, economia e capacidade de seus sistemas de saúde para atender às necessidades mais básicas da população que deles dependem (LITEWKA; HEITMAN, 2020).

No Brasil, o Supremo Tribunal Federal apontou o caminho para a interpretação sobre a distribuição das competências dos entes federativos no que tange à gestão das políticas para contenção e atenuação da pandemia (STF, 2020). O desgoverno na esfera de boa parte dos 
representantes dos poderes executivo e legislativo implicou na necessidade de que a Corte Suprema do país determinasse a medida de atuação dos entes da federação, ainda que a decisão não tenha sido o suficientemente esclarecedora quando esmiuçadas as questões práticas concernentes à administração da crise.

Como humana condição universal, não há o que se discutir na esfera do reconheciemnto da vulnerabilidade ontológica, categoricamente chamada de intrínseca. A ideia então é descotinar o processo de reconhecimento das vulnerabilidades secundárias ou circuntanciais que se potencializaram diante da pandemia.

Grupos vulneráveis são pessoas desproporcionalmente expostas a riscos, pelas suas condições individuais e abstratas, mas quem está incluído nesses grupos pode passar a não estar mais, ou seja, há uma dinâmica que possibilita a mudança. Essa ideia de vulnerabilidade reflete a linha interpretativa de Florencia Luna (2008) que atenta para a necessidade de compreensão desse conceito a partir do pressuposto da dinamicidade. A vulnerabilidade passaria a ser uma dimensão do sujeito passível de mudança a partir das relações que ele estabelece e a partir da situação em concreto avaliada. A título de exemplo, pode-se considerar que uma pessoa não considerada vulnerável no início de uma pandemia pode se tornar uma pessoa vulnerável.

Fica evidente, dessa forma, que a pandemia tornou-se elemento de maior vulneração dos indivíduos, já que várias relações sociais foram modificadas e/ou atingidas por uma consequência não benéfica.

Logo, "os riscos de perda repentina de renda ou acesso a apoio social têm consequências que são difíceis de estimar e constituem um desafio na identificação de todos aqueles que podem se tornar vulneráveis", de modo que, em meio à pandemia do COVID-19, "vulneráveis grupos não são apenas idosos, aqueles com problemas de saúde e comorbidades, ou pessoas sem-teto ou sem moradia, mas também pessoas de um gradiente de grupos socioeconômicos que pode ter dificuldade em lidar financeiramente, mentalmente ou fisicamente com a crise" (EDITORIAL LANCET, 2020).

A vulnerabilidade, enquanto categoria genérica e universal relacionada à espécie humana, passa a ganhar dimensões de especificidade em países como o Brasil. Vulneráveis, pois, são os sujeitos sociais desfavorecidos pela condição socioeconômica, idosos, gestantes (MASCARENHAS et al, 2020), pessoas com problemas de saúde, negros, índios (FIOCRUZ, 2020) e os profissionais da saúde, muitas vezes submetidos à situações inadequadas quanto à exposição do vírus e a desgastes físico e mental.

A pandemia decortina um complexo de vulnerabilidades sociais que influenciam também as relações em saúde. A perda do emprego ou da renda deságua em consequências que 
se relacionam com a saúde enquanto bem universal, o que inclui o acesso à informação, o acesso aos serviços de saúde e a exposição mais acentuada a riscos de contaminação por sobrevivência.

A dimensão histórica da relação entre médicos e pacientes atesta como característica evidente a assimetria. O elemento assimétrico é explicado pela perspectiva que diferencia os sujeitos no que tange ao acesso ao conhecimento, à técnica e ao saber científico. Assim, a relação médico-paciente, em sua própria natureza, foi constituída por uma desigualdade essencial que contingencia o sujeito doente à uma condição de hipossuficiência.

Ao longo dos últimos anos, o paradigma da assimetria passou a ser abrandado pela necessidade de reconhecer direitos dos pacientes e admitir o seu processo de emancipação dentro da relação. A saída para abrandar o elemento assimétrico foi empoderar o paciente através do cada vez mais fundamental reconhecimento da sua autonomia. A recepção da autonomia do paciente como pressuposto indispensável para o desenvolvimento adequado da sua relação com o médico contou com a concepção de que era fundamental promover a comunicação ética das informações entre ambas as partes e a noção de que os consentimentos precisavam representar decisões compreendidas e reais. O processo de mudança permanece em curso, sendo necessária a construção de reflexões bioéticas, jurídicas e médicas como colaboradoras a um bom resultado.

Ressalta-se que o processo de emancipação do paciente encontra circunstâncias bastantes relativas, na medida em que as realidades sociais se diferenciam e influenciam na possibilidade de acesso à saúde.

A relação médico-paciente, diante da COVID-19, ganha contornos importantes quanto à condição de vulnerabilidade das partes. O primeiro contorno é a constação antes apontada de que a enfermidade trazida pela pandemia é ainda pouco explorada pela Ciência e isso muda a margem de segurança com que se pode pensar a relação quando se trata de doenças pouco conhecidas.

A mudança na relação médico-paciente pode ser pensada em esfera geral, dada a necessidade de cuidados sanitários, em ambitos clínico, hospitalar e laboratorial, em prol da não contaminação. Pacientes portadores de patologias prévias à deflagração da pandemia demandam orientações e cuidados dos profissionais de saúde que os acompanham. Os estudos pandêmicos apontam, constantemente, a diferença de contaminação por pacientes em condições de comorbidades, como hipertensão; diabetes; problemas respiratórios; neoplasias; doenças crônicas e outras (OPAS/ OMS, 2021). A possibilidade de manifestação da forma grave da doença em pacientes que integram o grupo de risco é evidência de vulnerabilidade que deve ser considerada pelos profissionais para fins de informações. Compete ao médico ou ao profissional 
de saúde informar aos pacientes que estão na condição de vulnerabilidade acrescida, advinda do pretencimento ao grupo de risco, os males de uma possível contaminação.

Em esfera específica, quando o objeto da relação é o tratamento da doença pandêmica, há outros elementos a serem considerados. O primeiro deles é pressuposto a qualquer relação dessa natureza - a adequação das orientações pertinentes ao quadro clínico do paciente com a doença. Naturalmente, o caso concreto definirá se os esclarecimentos devem ser conferidos diretamente ao paciente ou à sua família. O internamento emergencial e o agravamento da doença vulnerabilizam o paciente em sua dimensão de informação, liberdade e autonomia. Competirá aos profissionais de saúde o cuidado minucioso com a paciente inconsciente (muitas vezes entubado) em prol de garantir o acesso às informações sobre sua saúde pelos seus familiares. A necessidade de resguardar a família da possibilidade de contaminação pelo contato de direto precisa ser, na medida do possível, atenuada por um acesso cuidadoso e constante das informações sobre o doente.

Profissionais também podem estar em condições de vulnerabilidade. O estudo das vulnerabilidades dos profissionais de saúde perpassa também pela investigação da configuração das suas responsabilidades à luz dos pressupostos éticos profissionais (para médicos, dinamizados pelo Código de Ética Médica (CFM, 2019) e pelas Resoluções do seu respectivo Conselho de Classe) e do sistema jurídico. Sabe-se que a realidade da pandemia descortinou uma série de situações não vivenciadas antes pela maioria dos seres humanos, em especial, pelos profissionais da saúde, como o desconhecimento sobre o protocolo adequado para tratar a doença, seu grau acentuado de disseminação, a escassez de recursos em ambientes hospitalares e clínicos, a abertura ou a inexistência de novos leitos em Unidades de Terapia Intensiva dentre tantas outras circunstâncias que compõem o cenário de exposição, risco e incerteza no qual eles estão inseridos.

\footnotetext{
Por sermos uma espécie essencialmente subjetiva, necessitamos do olhar do Outro para ratificar a nossa própria humanidade. Desta forma, somos vulneráveis porque somos subjetivos. É exatamente deste ponto nevrálgico que parte a (re)construção da ideia de vulnerabilidade médica no contexto pandêmico: o reconhecimento pelo próprio paciente de que, diante de um cenário de múltiplas incertezas, o médico, assim como todos os seres humanos, é e se coloca a todo tempo em um papel que revela a sua condição de vulnerabilidade acrescida. A consciência de finitude e o reconhecimento desta por ambas as partes aproxima e tende a uniformizar de forma sutil e visceral a relação médico-paciente (MEIRELLES; ARAÚJO FILHO; VERDIVAL, 2021, p.1).
}

O Sistema Único de Saúde (SUS), voltado ao atendimento gratuito a todo e qualquer cidadão brasileiro, tão fundamental ao combate do cenário pandêmico, vem, ao longo dos anos, 
vilipendiado e negligenciado pelos governantes que ocuparam e ocupam as diversas esferas de poder político. As falhas do SUS são fruto da inoperante política brasileira construída ao longo de séculos, manifestadas por deficiências estruturais relacionadas à incapacidade de gestão e à distribuição insuficiente e equivocada de recursos.

A dimensão dos riscos agregados pelo contexto pandêmico não tem o condão de anular, à luz das regras éticas e jurídicas brasileiras, a dinâmica da sistemática da responsabilidade dos profissionais da saúde no que tange às possíveis condutas lesivas a pacientes. Pode-se pensar, no entanto, que a constatação da vulnerabilidade das categorias profissionais da saúde está relacionada à necessidade de atentar para uma real e justa construção dos motivos justificadores da responsabilização. O contexto e os fundamentos que motivaram a conduta que ocasionou determinado dano precisam partir de uma análise ponderada e ter em conta riscos, escassez de recursos (que envolvem suprimentos hospitalares e, em especial, profissionais disponíveis) e condições físicas e mentais dos sujeitos envolvidos.

Em termos pandêmicos, parte-se da necessidade de ponderação das circunstâncias em concreto, como "a alta demanda, a incerteza com as técnicas e até o excesso de informações disponíveis, mas por vezes contraditórias e ainda sem comprovação científica”, que produzem um "quadro em que a responsabilidade civil do profissional de saúde, já considerada subjetiva no Direito brasileiro, deve ser mais criteriosa para sua configuração". Assim, "em virtude da concorrência de vários fatores desfavoráveis ao profissional de saúde, é normal que o operador do Direito não entenda pela responsabilização daquele por pequenas falhas. Há que se levar em conta o que dele era exigível diante do caso concreto" (FREIRE DE SÁ; ANTUNES; TORQUATO, 2020, p.3).

O panorama delineado evidencia a necessidade de conceber que o crescimento dos sujeitos em vulnerabilidade é hoje a principal realidade social do Brasil. Diversos sujeitos, antes vulneráveis, sofreram novo processo de vulneração. Outros sujeitos, não categoricamente vulneráveis, passaram a integrar grupos socialmente fragilizados.

A Bioética, enquanto disciplina que busca orientar as relações da vida, a partir de pressupostos éticos e protetivos, tem muito a colaborar diante da perspectiva pandêmica (OGBOGU; HARDCASTLE, 2020). Mesmo com múltiplas matrizes de estudo, todas elas podem ser vetores de auxílio social para redimensionar os impactos gerados pelo agravamento das vulnerabilidades humanas durante e após a crise pandêmica. Os comandos da Justiça e Beneficência, da Bioética principialista, muito colaboram para a construção de políticas públicas verdadeiramente adequadas, principalmente em países que agregam significativas desigualdades sociais como o Brasil. 
Necessário será redimensionar as vulnerabilidades acentuadas pelo contexto pandêmico, a partir de investigação que identifique essa realidade. A vulneração dos sujeitos, o que inclui a relação médico-paciente, é uma evidente consequência da pandemia e precisa ser reconhecida e encarada pelo Estado e pela sociedade.

\section{CONCLUSÃO}

Na história recente da humanidade, a pandemia é o evento catastrófico que acentuou, ainda mais, o que já era desigual e o que tendia à desigualdade. $\mathrm{O}$ descortinamento das vulnerabilidades, agravadas pela pandemia e pelo contexto sócio-político brasileiro, já demanda estudo minucioso em prol da execução de políticas públicas adequadas e voltadas aos sujeitos e aos grupos mais prejudicados.

No Brasil, assiste-se à incapacidade técnica de parte significativa de gestores públicos e ao processo, cada vez mais evidente, de não harmonização entre os entes federativos em prol de uma política colaborativa que combata de maneira justa e eficaz a disseminação do vírus, também agravada pela falta e/ou inadequação de planejamento quanto à distribuição da vacina.

A vulnerabilidade, cada vez mais, no Brasil, aproxima-se de uma categoria frequentemente recepcionada pelos estudos da Bioética e pela atividade jurisdicional, já que reflete as condições reais dos sujeitos que sofreram acentuado processo de vulneração. Devese, então, compreender que o aumento das condições de vulnerabilidade, como consequência do processo pandêmico no país, passa a integrar a esfera de responsabilidade, tanto da sociedade quanto do Estado, na medida em que a consciência e o combate precisam andar em paralelo em função de resultados efetivos.

Admitida a vulnerabilidade, primeiro, como uma condição humana universal, segundo como uma condição dinâmica que oscila e que evidencia pressupostos individuais e abstratos de determinadas pessoas ou grupos, percebe-se o surgimento de novos sujeitos vulneráveis e sujeitos ainda mais vulnerabilizados.

Novos elementos surgem, no âmbito das relações em saúde, e se tornam essenciais à construção adequada dessa relação no que tange aos profissionais e ao paciente. O paciente, na sua condição de vulnerabilidade previamente conhecida, os profissionais, aqui incluídos os médicos, como novos vulneráveis, considerando a contextualização dos fatos apontados relacionados ao processo pandêmico.

A relação médico-paciente, na pandemia, ganha contornos redimensionados pela constatação das vulnerabilidades dos sujeitos que a integram. As consequências do processo 
pandêmico acentuam a noção de vulnerabilidade, antes, somente assumida como condição indiscutível do paciente. Profissionais da saúde passam, também, à condição de sujeitos vulneráveis, na medida em que são demandados em condições extremas e se arriscam, diariamente, à contaminação.

\section{REFERÊNCIAS BIBLIOGRÁFICAS}

AYRES, José Ricardo; FRANÇA JÚNIOR, I; CALAZANS, G. J., \& SALETTI FILHO, H. C. O conceito de vulnerabilidade e as práticas de saúde: novas perspectivas e desafios. In: D. Czeresnia \& C. M. Freitas (Orgs.). Promoção da saúde - conceitos, desafios, tendências. Rio de Janeiro: Fiocruz, 2003.

BEAUCHAMP, T.; CHILDRESS, J. Principles of Biomedical Ethics. New York: Oxford University Press, 1979.

BERTOLOZZI, Maria Rita et al. Os conceitos de vulnerabilidade e adesão na Saúde Coletiva. Revista Escola Enfermagem USP, 2009; 43(Esp 2):1326-30.

BRASIL. CNS. Resolução 466/2012. Disponível em: https://bvsms.saude.gov.br/bvs/saudelegis/cns/2013/res0466_12_12_2012.html Acesso em: 05 dez. 2020.

BRASIL. CNS. Resolução 510/2016. Disponível em: https://bvsms.saude.gov.br/bvs/saudelegis/cns/2016/res0510_07_04_2016.html Acesso em: 05 dez. 2020.

CALDAS DOS SANTOS, J.F; SIQUEIRA, A; PRAÇA, H; ALBUQUERQUE, H. Vulnerabilidade a formas graves de COVID-19: uma análise intramunicipal na cidade do Rio de Janeiro, Brasil. Cad. Saúde Pública, 36(5), 2020. Disponível em: 2020.https://www.scielo.br/pdf/csp/v36n5/1678-4464-csp-36-05-e00075720.pdf. Acesso em: 08 out. 2020.

CAMPBELL, Alastair V. Pessoas vulneráveis: Experiencias e esperança. In: GARRAFA, Volnei; PESSINI, Leo (Orgs.). Bioética: Poder e Injustiça. Tradução Adair Sobral e Maria Stela Gonçalves. São Paulo: Edições Loyola, 2004, p.87-93.

CFM. Conselho Federal de Medicina. Código de Ética Médica. Brasília: Conselho Federal de Medicina, 2019.

EDITORIAL DEVELOPING WORLD BIOETHICS. The ethical challenges of the SARSCoV-2 pandemic in the global south and the global north - same and diferent. Developing World Bioethics. 2020. Disponível em: https://onlinelibrary.wiley.com/doi/10.1111/dewb.12263. Acesso em: 15 out. 2020.

EDITORIAL LANCET. Redefining vulnerability in the era of COVID-19. Lancet 2020; 395:1089. Disponível em: 
https://www.thelancet.com/action/showPdf?pii=S01406736\%2820\%2930757-1. Acesso em: 05 nov. 2020.

FIOCRUZ. Núcleo de Métodos Analíticos para Vigilância em Epidemiologia do PROCC/Fiocruz e EMAp/FGV 1 Grupo de Trabalho sobre Vulnerabilidade

Sociodemográfica e Epidemiológica dos Povos Indígenas no Brasil à Pandemia de COVID-19 2 e colaboradores. Risco de espalhamento da COVID-19 em populações indígenas: considerações preliminares sobre vulnerabilidade geográfica e sociodemográfica. Ministério da Saúde: Fiocruz. Disponível em:

https://portal.fiocruz.br/sites/portal.fiocruz.br/files/documentos/relatorios_tecnicos_-_covid19_procc-emap-ensp-covid-19-report4_20200419-indigenas.pdf Acesso em: 11 nov. 2020.

FREIRE DE SÁ, M; ANTUNES, I; TORQUATO, B. Responsabilidade civil dos profissionais de saúde ante diante da Covid-19. Consultor Jurídico, abril 2020, 3. Disponível em: https://www.conjur.com.br/2020-mai-16/direito-pos-graduacao-responsabilidadecivilprofissionais-saude-covid-19?imprimir=1. Acesso em: 13 out. 2020.

GARCIA, Maria. Limites da Ciência. A dignidade da pessoa humana e a ética da responsabilidade. São Paulo: Revista dos Tribunais, 2004.

GARRAFA, Volnei. Da bioética de princípios a uma bioética interventiva. Revista Bioética. Conselho Federal de Medicina. Brasília. 13 (1), 2005. Disponível em: https://revistabioetica.cfm.org.br/index.php/revista_bioetica/article/view/97/102. Acesso em: 05 out. 2020.

HOSSNE, Willian Saad. Dos referenciais da Bioética - a vulnerabilidade. Bioethikos, Centro Universitário São Camilo, 2009;3(1):41-51.

JONAS, Hans. Técnica, Medicina e Ética. Sobre a prática do princípio Responsabilidade. Tradução do Grupo de Trabalho Hans Jonas da ANFOP. São Paulo: Paulus, 2013.

KOTTOW, Miguel. Comentários sobre Bioética, Vulnerabilidade e Proteção. In: GARRAFA, Volnei; PESSINI, Leo (Orgs.). Bioética: Poder e Injustiça. Tradução Adair Sobral e Maria Stela Gonçalves. São Paulo: Edições Loyola, 2004, p.71-79.

KUHN, Thomas. A estrutura das revoluções científicas. Tradução de Beatriz Vianna Boeira e Nelson Boeira. São Paulo: Perspectiva, 2007.

LITEWKA S.G.; HEITMAN E. LatinAmerican healthcare systems in times of pandemic. Developing World Bioeth. 2020;20: 69-73. Disponível em: https://doi.org/10.1111/dewb.12262. Acesso em: 08 out. 2020.

LUNA, Florência. Vulnerabilidad: la metáfora de las capas. Jurisprudencia Argentina, IV, fascículo n.1, 2008.

MACKIN, Ruth. Bioética, Vulnerabilidade e proteção. In: GARRAFA, Volnei; PESSINI, Leo (Orgs.). Bioética: Poder e Injustiça. Tradução Adair Sobral e Maria Stela Gonçalves. São Paulo: Edições Loyola, 2004, p.59-70. 
MASCARENHAS, V.; CAROCI-BECKER, A; VENÂNCIO, K; BARALDI, N; DURKIN, A; RIESCO M. L. COVID-19 e a produção de conhecimento sobre as recomendações na gravidez: revisão de escopo. Rev. Latino-Americana. Enfermagem, v.28 Ribeirão Preto, 2020 Epub 26-Jun-2020. Disponível em:

https://www.scielo.br/scielo.php?script=sci_arttext\&pid=S010411692020000100606\&lng=pt $\& n r m=i s o \& t l n g=p t$ Acesso em: 03 nov. 2020.

MEIRELLES, Ana Thereza; ARAÚJO FILHO, José Edson; VERDIVAL, Rafael. Vulnerabilidade, Médicos e Pandemia. Disponível em:

http://cvmed.com.br/2021/01/05/vulnerabilidade-medicos-e-pandemia/ Acesso em: 06 jan. 2021.

MINAHIM, Maria Auxiliadora. Direito Penal e Biotecnologia. São Paulo: Revista dos Tribunais, 2005.

OGBOGU U, HARDCASTLE L. Bioethics and practical justice in the post-COVID-19 era. Developing World Bioethics. 2020; 00:1-5. Disponível em: https://onlinelibrary.wiley.com/doi/full/10.1111/dewb.12279. Acesso em: 05 out. 2020.

OPAS. OMS. Folha informativa COVID-19 - Escritório da OPAS e da OMS no Brasil. Disponível em: https://www.paho.org/pt/covid19\#risco. Acesso: 03 jan. 2021.

PATRÃO NEVES, Maria do Céu. Sentidos da vulnerabilidade: característica, condição e princípio. Revista Brasileira de Bioética, 2(2), 2006. Disponível em:

https://periodicos.unb.br/index.php/rbb/article/view/7966/6538. Acesso em: 05 out. 2020.

SASS, Hans-Martin. Promover a educação em saúde para enfrentar a doença e a vulnerabilidade. In: GARRAFA, Volnei; PESSINI, Leo (Orgs.). Bioética: Poder e Injustiça. Tradução Adair Sobral e Maria Stela Gonçalves. São Paulo: Edições Loyola, 2004, p.79-85.

STF. STF conclui julgamento de MPs que regulamentam competência para impor restrições durante pandemia. Maio 2020. Disponível em:

http://www.stf.jus.br/portal/cms/verNoticiaDetalhe.asp?idConteudo=442816. Acesso em: 02 nov. 2020.

WERNECK, G; CARVALHO, M. A pandemia de COVID-19 no Brasil: crônica de uma crise sanitária anunciada. Cad. Saúde Pública 2020; 36(5), 2020. Disponível em:

https://blog.scielo.org/wp-content/uploads/2020/05/1678-4464-csp-36-05-e00068820.pdf.

Acesso em: 17 out. 2020. 